\title{
Study of Vanadium Doped ZnO Films Prepared by dc Reactive Magnetron Sputtering at Different Substrate Temperatures
}

\author{
Lijian Meng ${ }^{1,2, *}$, Vasco Teixeira², and M. P. Dos Santos ${ }^{3}$ \\ ${ }^{1}$ Departamento de Física, Instituto Superior de Engenharia do Porto, Rua Dr. António Bernardino de Almeida 431, \\ 4200-072 Porto, Portugal \\ ${ }^{2}$ Centro de Física, Universidade do Minho, Campus de Azurém, 4800-058 Guimarães, Portugal \\ ${ }^{3}$ CEFITEC, Departamento de Física, Faculdade de Ciências e Tecnologia-FCT, Universidade Nova de Lisboa, \\ 2829-516 Caparica, Portugal/Departamento de Física, Escola de Ciências e Tecnologia-ECT, \\ Universidade de Évora, 7000-671-Évora, Portugal
}

\begin{abstract}
$\mathrm{ZnO}$ films doped with vanadium $(\mathrm{ZnO}: \mathrm{V})$ have been prepared by dc reactive magnetron sputtering technique at different substrate temperatures $\left(R T-500^{\circ} \mathrm{C}\right)$. The effects of the substrate temperature on ZnO:V films properties have been studied. XRD measurements show that only ZnO polycrystalline structure has been obtained, no $\mathrm{V}_{2} \mathrm{O}_{5}$ or $\mathrm{VO}_{2}$ crystal phase can be observed. It has been found that the film prepared at low substrate temperature has a preferred orientation along the (002) direction. As the substrate temperature is increased, the (002) peak intensity decreases. When the substrate temperature reaches the $500{ }^{\circ} \mathrm{C}$, the film shows a random orientation. SEM measurements show a clear formation of the nano-grains in the sample surface when the substrate temperature is higher than $400^{\circ} \mathrm{C}$. The optical properties of the films have been studied by measuring the specular transmittance. The refractive index has been calculated by fitting the transmittance spectra using OJL model combined with harmonic oscillator.
\end{abstract}

Keywords: Zinc Oxide, Vanadium Oxide, Thin Films, Sputtering, Optical Properties.

\section{INTRODUCTION}

Dilute magnetic semiconductors (DMS) have properties intermediate between a magnetic element and a nonmagnetic semiconductor. In general, they are obtained by doping some non-magnetic semiconductor with transition metal elements. Although most of them have low Curie temperature, it has been theoretically predicted that transition metals (TM) like V, Cr, Fe, Co and $\mathrm{Ni}$ doped $\mathrm{ZnO}$ materials can have room temperature ferromagnetism. ${ }^{1-2}$ These materials can be very interesting because of their potential applications in semiconductor spintronics, ${ }^{3}$ which intends to extend the field of applications of the usual electronic devices by including also the effects of the spin of the electrons. The magnetization of these TM-doped $\mathrm{ZnO}$ films strongly depends on the preparation parameters, and recently better controlled samples have been produced and problems such as thickness effects, growth temperatures

\footnotetext{
*Author to whom correspondence should be addressed
}

and doping level effects have been studied systematically on $\mathrm{Mn}$ and $\mathrm{Co}$ doped $\mathrm{ZnO}$ films. ${ }^{4-9}$ However, vanadium doped $\mathrm{ZnO}$ has not been studied widely although it has been predicted room temperature ferromagnetism. Only pulsed laser deposited vanadium doped $\mathrm{ZnO}$ films magnetic properties have been reported. ${ }^{10-11}$ For the applications, Vanadium doped $\mathrm{ZnO}$ film is interesting not only in terms of its room temperature ferromagnetism, but also because it is a transparent ferromagnetic material, and then further detailed study on vanadium doped $\mathrm{ZnO}$ films is necessary. In this paper, we have used a different preparation technique where we can have a good control of the experimental parameters, and so vanadium doped $\mathrm{ZnO}$ films at different substrate temperatures have been prepared by dc reactive magnetron sputtering and we studied the structural and optical properties of these vanadium doped $\mathrm{ZnO}$ films. We intend to show that this is also a competitive preparation technique, for which we can easily optimise the preparation parameters for some specific application. 


\section{EXPERIMENTAL DETAILS}

Vanadium doped $\mathrm{ZnO}$ films were prepared on microscope glass slides by using a home-made dc reactive magnetron sputtering system. The target is a zinc metal with a purity of $99.99 \%$. Small pieces of vanadium metal were put on the top of the zinc metal target in order to obtain the vanadium doped $\mathrm{ZnO}$ films. The distance between the target and the substrate is about $50 \mathrm{~mm}$. The total and oxygen reactive gas pressures are $9 \times 10^{-3}$ mbar and $3 \times 10^{-3}$ mbar, respectively A constant sputtering current mode is used and is kept at $0.3 \mathrm{~A}$ for all experiments. The deposition time was about $20 \mathrm{~min}$. The substrate temperature was varied from room temperature until $500{ }^{\circ} \mathrm{C}$. The film thickness was obtained by fitting the transmittance spectra and has been confirmed by SEM measurements. The concentration of vanadium in $\mathrm{ZnO}$ films were determined by Energy Dispersive X-ray Spectroscopy (EDS).

\section{RESULTS AND DISCUSSION}

The vanadium concentration in $\mathrm{ZnO}$ film prepared at different substrate temperatures is about $8 \mathrm{~mol} \%$ which is measured by EDS. The deposition rate keeps at a constant value (about $40 \mathrm{~nm} / \mathrm{min}$ ) as the substrate temperature is increase from RT to $300{ }^{\circ} \mathrm{C}$. However, the deposition rate decreases when the substrate temperature is higher than $300{ }^{\circ} \mathrm{C}$. When the substrate temperature is increased from $300{ }^{\circ} \mathrm{C}$ to $500{ }^{\circ} \mathrm{C}$, the deposition rate decreases from $40 \mathrm{~nm} / \mathrm{min}$ to $35 \mathrm{~nm} / \mathrm{min}$. This variation of the deposition rate agrees neither with that of the $\mathrm{ZnO}$ films nor with that of the $\mathrm{V}_{2} \mathrm{O}_{5}$ films prepared by the same technique at different substrate temperatures. ${ }^{12-13}$ For the $\mathrm{ZnO}$ films, the deposition rate did not show a clear variation with the substrate temperature. ${ }^{12}$ But for the $\mathrm{V}_{2} \mathrm{O}_{5}$ films, the deposition rate increased with the substrate temperature. ${ }^{13}$ Therefore, the variation of the deposition rate of $\mathrm{ZnO}: \mathrm{V}$ films could not be related with the doping of the vanadium in $\mathrm{ZnO}$ films. It seems that the variation of the deposition rate results from the variation of the cathode potential. It has been found that when the substrate temperature is higher than $300{ }^{\circ} \mathrm{C}$, the same sputtering current $(0.3 \mathrm{~A})$ can be reached with a low cathode potential. It means that the sputtering power decreases and may result in a decrease of the deposition rate. In addition, the re-evaporation from the substrate at high substrate temperature may also result in a decrease of the deposition rate.

$\mathrm{X}$-ray diffraction (XRD) of $\mathrm{ZnO}: \mathrm{V}$ films deposited at different substrate temperatures are shown in Figure 1. All the films show $\mathrm{ZnO}$ structure, no vanadium oxide crystal phase can be observed. Our previous results showed that the vanadium exists in these films as $\mathrm{V}^{5+}$ state. $^{14}$ Although XRD measurements did not show any $\mathrm{V}_{2} \mathrm{O}_{5}$ crystal phase, it can not be concluded that no $\mathrm{V}_{2} \mathrm{O}_{5}$ phase exists in these $\mathrm{ZnO}: \mathrm{V}$ films. The $\mathrm{V}_{2} \mathrm{O}_{5}$ may exist in these $\mathrm{ZnO}: \mathrm{V}$ films as the amorphous phase. It can be seen that

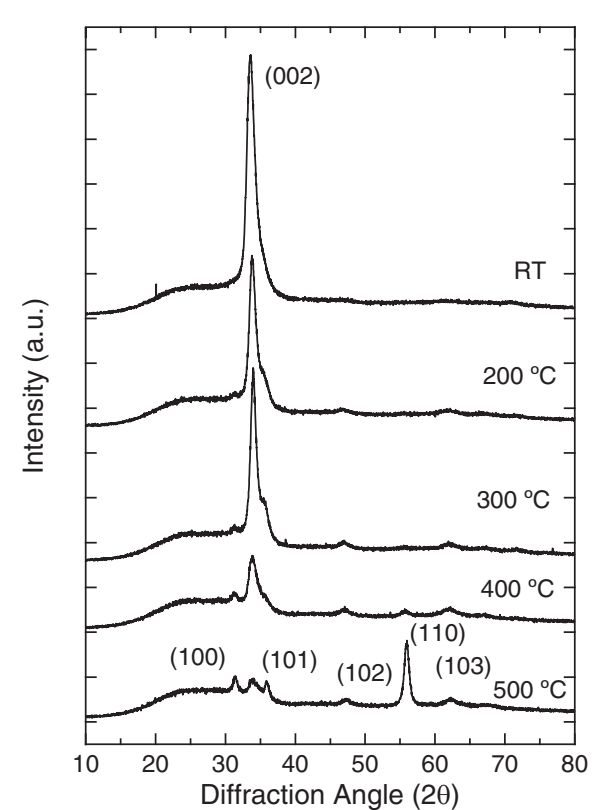

Fig. 1. X-ray diffraction patterns of $\mathrm{ZnO}: \mathrm{V}$ films prepared at different substrate temperatures.

the film prepared at room temperature is $c$-axis oriented perpendicular to the substrate surface, as evidenced from the strong (002) diffraction peak. As the substrate temperature is increased, the preferred orientation along the (002) direction diminishes. When the substrate temperature reaches $500{ }^{\circ} \mathrm{C}$, the film shows a random orientation. This variation of the structure is different from the pure $\mathrm{ZnO}$ films, in which the preferred orientation along the (002) direction still exists at high substrate temperature. ${ }^{12}$ Therefore, this structure variation at high substrate temperature may result from the vanadium doping. It means the vanadium doping can restrain the crystal growth and result in the vanish of the preferred orientation. It seems that the vanadium doping effect on the structure of $\mathrm{ZnO}$ films only appears clearly at high substrate temperature. Our previous study on vanadium oxide films show that the vanadium oxide film prepared at low substrate temperature has an amorphous structure, only the films prepared at high substrate temperature show a polycrystalline structure. ${ }^{13}$ These facts may give some explanations on the structure variation shown in Figure 1. Although no vanadium oxide phase can be observed even for $\mathrm{ZnO}: \mathrm{V}$ films prepared at high substrate temperatures, there is a tendency to form vanadium oxide phase at these high substrate temperatures and may result in a variation of these $\mathrm{ZnO}: \mathrm{V}$ films.

Figure 2 shows the SEM photographs of the $\mathrm{ZnO}: \mathrm{V}$ films deposited at different substrate temperatures. It can be seen that the surface topography does not show a clear variation when the substrate temperature is lower than $300{ }^{\circ} \mathrm{C}$. However, when the substrate temperature is higher than $400{ }^{\circ} \mathrm{C}$, the formation of grains can be obviously observed. The average grain size along the sample surface is about $300 \mathrm{~nm}$. Although it is well known that the 

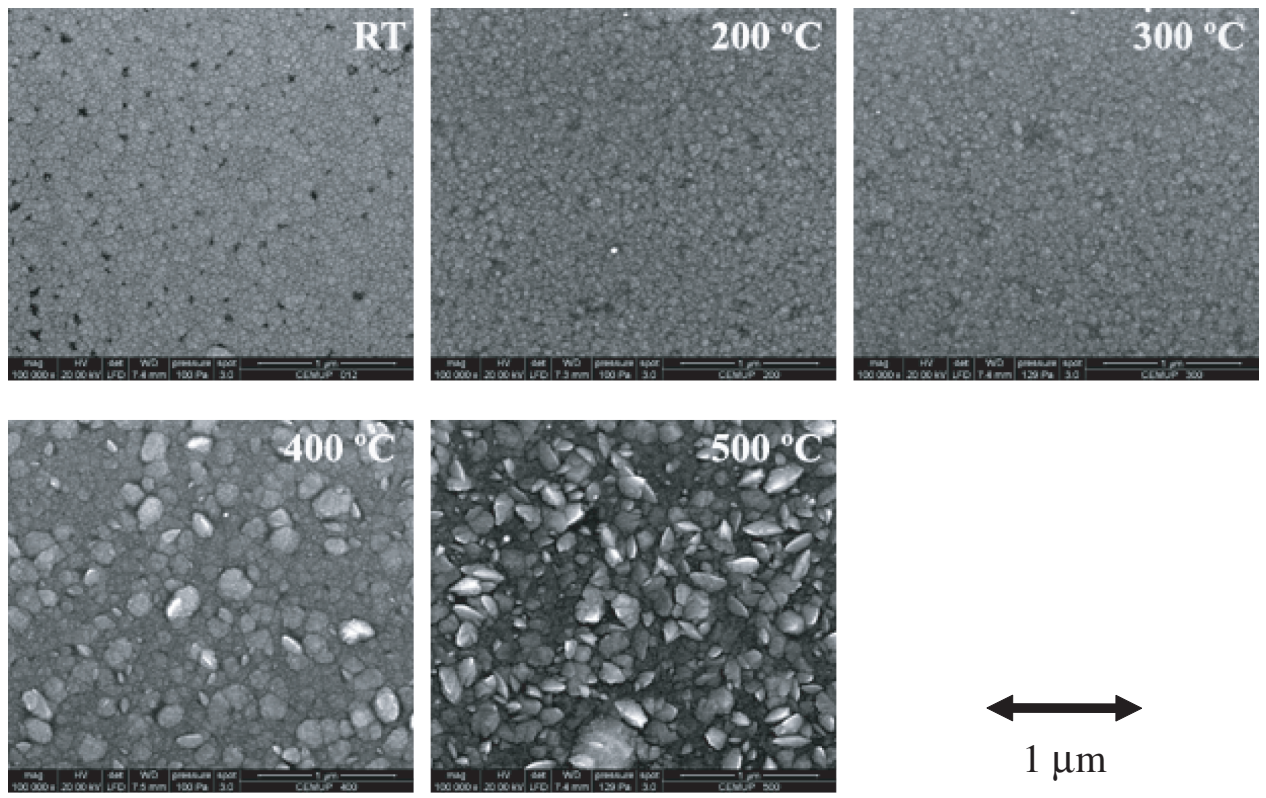

Fig. 2. The SEM photographs of $\mathrm{ZnO}: \mathrm{V}$ films deposited at different substrate temperatures.

high substrate temperature is favourable for growth of the grains, the scene is totally different for $\mathrm{ZnO}$ and $\mathrm{ZnO}: \mathrm{V}$ films prepared at different substrate temperatures as it can been from our previous results on pure $\mathrm{ZnO}$ films. ${ }^{12}$ For pure $\mathrm{ZnO}$ films prepared at high substrate temperatures, the films are composed by only large grains. However, the large grains are embedded among the small grains for the $\mathrm{ZnO}: \mathrm{V}$ films prepared at high substrate temperatures. It means that vanadium doping modifies significantly the $\mathrm{ZnO}$ film structure at high substrate temperature.

The specular optical transmissions of $\mathrm{ZnO}: \mathrm{V}$ films prepared at different substrate temperatures are given in Figure 3. It can be seen that the transmittance of $\mathrm{ZnO}: \mathrm{V}$ films decreases as the substrate temperature is increased. As neither $\mathrm{ZnO}$ nor $\mathrm{V}_{2} \mathrm{O}_{5}$ is an absorb medium, the loss of the light may be caused by the light scattering due to the inhomogeneity and the surface roughness of the films. The difference of the specular transmittance for $\mathrm{ZnO}: \mathrm{V}$ films prepared at room temperatures and $300{ }^{\circ} \mathrm{C}$ substrate temperatures is not very clear. However, the specular transmittance of $\mathrm{ZnO}: \mathrm{V}$ film prepared at $500{ }^{\circ} \mathrm{C}$ substrate temperature shows a clear decrease. From Figure 2 it can be seen that the film prepared at $500{ }^{\circ} \mathrm{C}$ substrate temperatures has a rough surface, it will increase the intensity of the scattering light and result in low specular transmittance.

In order to get the refractive index $n$ of these $\mathrm{ZnO}: \mathrm{V}$ films, the transmittance of these films have been fitted using OJL model. ${ }^{15-16}$ The refractive index of the $\mathrm{ZnO}: \mathrm{V}$ films prepared at different substrate temperatures are given in Figure 4. The results show that the film prepared at $300{ }^{\circ} \mathrm{C}$ has the highest refractive index. In general, according to the Thornton structure model, ${ }^{17}$ the high substrate temperature is favourable for the dense structure and will result in a high refractive index. That is why the refractive index is increased as the substrate temperature is increased from RT to $300{ }^{\circ} \mathrm{C}$. However, the refractive index decreases when the substrate temperature is higher than $300{ }^{\circ} \mathrm{C}$. This abnormal variation of the refractive index could be related with the vanadium doping. From our previous results, ${ }^{12-13}$ the refractive index of $\mathrm{V}_{2} \mathrm{O}_{5}$ film is lower than that of $\mathrm{ZnO}$ film. As it has been discussed above, the vanadium doping effect only appears clearly when the substrate temperature is higher than $300{ }^{\circ} \mathrm{C}$. It may result in a decrease of the refractive index.

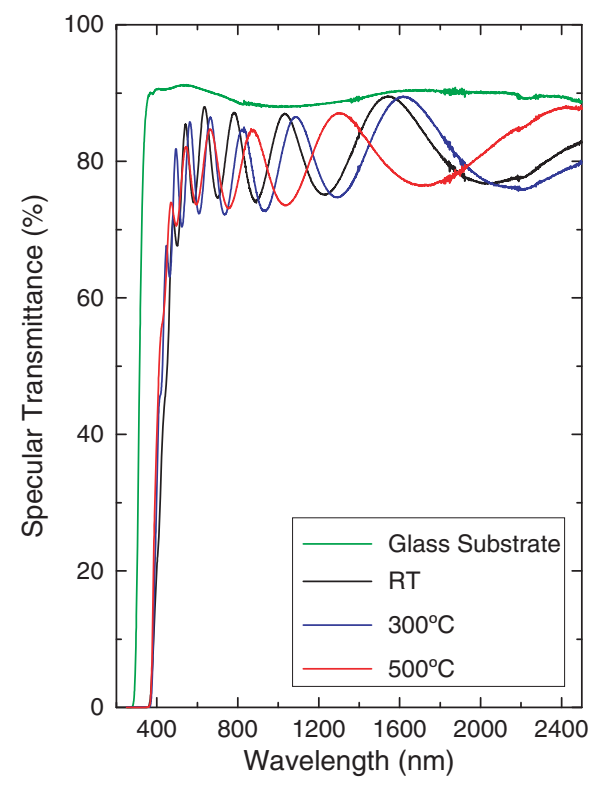

Fig. 3. Specular optical transmission of the $\mathrm{ZnO}: \mathrm{V}$ films prepared at different substrate temperatures. 


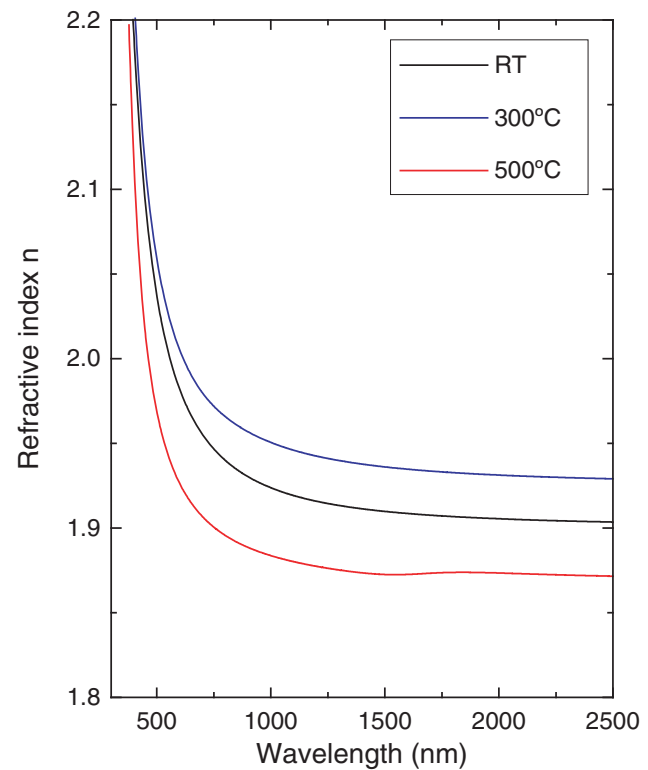

Fig. 4. The refractive index as a function of the wavelength for the $\mathrm{ZnO}: \mathrm{V}$ films prepared at different substrate temperatures.

The film thickness is also obtained by the fitting. The results got by fitting and by SEM measurement are quite similar. The films prepared at the substrate temperature lower than $300{ }^{\circ} \mathrm{C}$ have a thickness of $800 \mathrm{~nm}$ and the film prepared at $500{ }^{\circ} \mathrm{C}$ substrate temperature have a thickness of $700 \mathrm{~nm}$. It means that the fitting model, which has been used, is suitable for these films. The optical band gap of the films prepared at different substrate temperatures was also calculated. The optical band gap increases from $3.14 \mathrm{eV}$ to $3.24 \mathrm{eV}$ as the substrate temperature is increased from room temperature up to $500{ }^{\circ} \mathrm{C}$. These values are similar to the $\mathrm{ZnO}$ films without any doping. ${ }^{18}$ This means that vanadium doping at this level does not give a clearly modification of the band gap of $\mathrm{ZnO}$ films.

\section{CONCLUSIONS}

Vanadium doped $\mathrm{ZnO}$ films have been deposited onto glass substrate by dc reactive magnetron sputtering technique at different substrate temperatures. The vanadium concentration in $\mathrm{ZnO}$ films is about $8 \mathrm{~mol} \%$. Although no $\mathrm{V}_{2} \mathrm{O}_{5}$ crystal phase can be observed for all the samples, the influence of the vanadium doping on $\mathrm{ZnO}$ films structure can be observed, especially, when the substrate temperature is higher than $300{ }^{\circ} \mathrm{C}$. Both the structure and the optical properties of $\mathrm{ZnO}$ films can be clearly modified by vanadium doping at high substrate temperatures (higher than $300{ }^{\circ} \mathrm{C}$ ). This confirms our aim to show the possibility of control of the samples properties by easily changing the preparation parameters.

\section{References and Notes}

1. K. Sato and H. Katyama-Yoshida, Semicond. Sci. Technol. 17, 367 (2002).

2. K. Sato and H. Katyama-Yoshida, Jpn. J. Phys., Part 2 39, L555 (2000).

3. S. J. Pearton, C. R. Abernathy, D. P. Norton, A. F. Hebard, Y. D. Park, L. A. Boatner, and J. D. Budai, Mat. Sci. Eng. R 40, 137 (2003).

4. U. Ozgur, Ya. I. Aliov, C. Liu, A. Teke, M. A. Reshchikov, S. Dogan, V. Avrutin, S. J. Cho, and H. Morkoc, J. Appl. Phys. 98, 041301 (2005).

5. S. J. Han, B. Y. Lee, J. S. Ku, Y. B. Kim, and Y. H. Jeong, J. Magn. Magn. Mater. 272-276, 2008 (2004).

6. H. K. Yoshida and K. Sato, J. Phys. Chem. Solids 64, 1447 (2003).

7. Y. H. Jeong, S. J. Han, J. H. Park, and Y. H. Lee, J. Magn. Magn. Mater. 272-276, 1976 (2004).

8. J. L. Maurice, K. Rode, A. Anane, D. Imhoff, and J. P. Contour, Eur. Phys. J.-Appl. Phys. 33, 109 (1996).

9. A. F. Vyatkin, V. I. Zinenko, Y. A. Agaphonov, A. N. Pustovit, D. V. Roshchupkin, F. Reuss, C. Kirchner, R. Kling, and A. Waag, Nucl. Instrum. Meth. B 237, 179 (2005).

10. H. Saeki, H. Tabata, and T. Kawai, Solid State Commun. 120, 439 (2001).

11. S. Ramachandran, A. Tiwari, J. Narayan, and J. T. Prater, Appl. Phys. Lett. 87, 172502 (2005).

12. L. J. Meng, M. Andritschky, and M. P. Dos Santos, Vacuum 45, 19 (1994).

13. L. J. Meng, R. A. Silva, H. N. Cui, V. Teixiera, M. P. Santos, and Z. Xu, Thin Solid Films 515, 195 (2006).

14. L. W. Wang, L. J. Meng, V. Teixeira, S. G. Song, Z. Xu, and X. R. $\mathrm{Xu}$, Thin Solid Films 571, 3721 (2009).

15. A. Solieman and M. A. Aegerter, Thin Solid Films 502, 205 (2006).

16. M. Theiss, Hard and Software for Optical Spectroscopy, Aachen, Germany (2008).

17. J. A. Thornton, J. Vac. Sci. Technol. A 4, 3059 (1986).

18. L. J. Meng, M. Andritschky, and M. P. Dos Santos, Vacuum 44, 105 (1993).

Received: 12 September 2011. Accepted: 30 November 2011. 